\title{
Extroversion, Motivation and Russian L2
}

\author{
Antonio Carluccio ${ }^{1, *}$, Inna Rubakova $^{2}$, and Anastasiya Chetkina $^{3}$ \\ ${ }^{1}$ RUDN University, Department of Russian Language and Teaching Methods, 117198, Moscow, Russia \\ ${ }^{2}$ RUDN University, Department of Russian Language and Teaching Methods, 117198, Moscow, Russia \\ ${ }^{3}$ Moscow State University, Department of Neuro-and Pathopsychology, 119991, Moscow, Russia
}

\begin{abstract}
According to our previous research no attempt was made to find a multiple regression model, and consequently a correlation between the personality trait of an introvert/extrovert, individual motivation and an approach to Russian language L2. After a general review of the literature, we mainly concerned English as a foreign language (ESL). A research was made through a survey of Italian students learning Russian L2 outside the language environment in Italy. Starting from their answers we made a suitable score system, thanks to which we made a distribution, graphical and descriptive function for all the three variables. Finally a multiple regression model is provided to make reconciliation among the variables with statistical estimators of reliability.
\end{abstract}

\section{Introduction}

Learning a new language is a time-consuming process which is strictly correlated to the student's inherent characteristics. These features may be both exogenous and endogenous, the former may be time constraint, language environment and social linkages, the latter are tightly linked with the student's innermost characteristics, like motivation, future usability of the L2 language and personal attitude to the language learning process and to the external world. Individual differences were proved to have statistical relevance to predict successful outcomes in language learning. Research on the peculiarities of the L2 acquisition has seen an unprecedented increase during the last years for an amount of more than 400 works [1].

However, the study of the relations between personality and L2 acquisition has a long history. Among the earliest examples there was a study on the relation between anxiety and second language acquisition, observing that anxiety may be either facilitating or debilitating [2]. Further studies found that language anxiety has a dominant negative effect on L2 learning [3]. A Foreign Language Classroom Anxiety Scale (FLCAS), assessing three components of anxiety (communication apprehension, test anxiety, and fear of negative evaluation) was made to measure the detrimental effect on language learning [4]. Other researchers have also developed measures to cope with specific language anxiety, but a deeper analysis of the literature on this matter goes beyond the scope of our work. Another factor influencing the L2 acquisition is language aptitude, which is a general term referring to those verbal abilities that facilitate L2 learning. Language aptitude, in the same way as anxiety, has also a long history of research. The Modern Language Aptitude Test (MLAT) [5] is the most widely used to capture the effects derived from aptitude and constitutes the cornerstone from which other tests are inspired, such as the Elementary Form of the Modern Language Aptitude Test [6] and the Language Aptitude Battery [7]. The MLAT consists of five subtests: Number Learning, Phonetic Script, Spelling Clues, Words in Sentences, and Paired Associates, the last three of which are recommended as a short form [5]. Research indicates that achievement in a L2 is positively related to language aptitude. Correlations between measures of language aptitude and various measures of L2 achievement are generally positive and statistically significant, so that some scholars [8] see language aptitude to be the first determinant of good results in the L2 learning process. Some researchers have observed the role of attitudes and motivation in L2 learning through several measures. An initial study [9] found that an individual's orientation to learn French as a L2 was linked with his motivations, attitudes toward French Canadians, and proficiency in French. The Attitude/Motivation Test Battery [3] was developed to measure these variables as well as other attitudinal and motivational attributes expected to be related with L2 learning.

This model has stimulated a large number of empirical studies and has resulted in attempts to synthesize the findings of such studies into a model which is called the socio-educational model [10-11]. Another important concept, opposed to anxiety, is self-confidence. Some authors proposed that self-confidence is a key indicator of the motivation to learn a L2, and that it is a positive function of contact with the L2 community [12]. According to his study, self-confidence constitutes the individual perception of confidence in the L2 and at the same time absence of anxiety while using a L2. His further studies with other scholars have found that indices of selfconfidence correlate significantly with other parameters of good results in the L2 learning process [12-17]. In

\footnotetext{
* Corresponding author: karluchchio-a@rudn.ru
} 
further studies were found reasons affecting the frequency of communication, such as the willingness to communicate in L2, motivation for learning a language, communicative competence perceived in L2, and contact with L2 speakers. Evidence demonstrate that personality traits and language-related affective variables, such as attitudes and anxiety, set the psychological framework for second language communication [18]. This study was further investigated finding that correlation between extraversion scores and linguistic variables depends largely on the type of linguistic material used. Research outcomes also indicate that studies of different aspects of individual differences and personality traits should be incorporated into further research on second language acquisition [19]. Other studies proved assertiveness to be explanatory variables of oral L2 production while no relationship was noted about self-consciousness [20]. Other scholars tried to find correlation between the overall degree of the perceived foreign accent in non-natives' English speech and some personal variables such as extraversion, anxiety, tough-mindedness, independence, self-control were analyzed and found a correlation coefficient [21]. Foreign language classroom anxiety (FLCA) was found to be significantly linked with neuroticism (anxiety), but moderately with psychoticism, and extraversion in a classroom context, strong correlations between FLCA values in L2, L3, and L4 indicated a certain degree of stability throughout the foreign languages known by the students [22]. Another research examined the effect of personality on the development of pragmatic competence among L2 English learners finding no significant effect of the introvertextrovert temperament on any aspects of pragmatic variable [23].

Some scholars aimed to find correlation between extraversion/introversion and results in a speaking test, finding data without a meaningful relationship, and with no significant difference between the performance of the extraverted and introverted groups on IELTS speaking test [24]. Further investigation about the relationship between personality traits and willingness to communicate (WTC) in a second language (L2 WTC) were made finding a positive correlation between academic achievement and L2 WTC. The interaction of the Big Five personality traits were proven to be a positive function of WTC in learning a second language [25]. In other studies openness to experience and extraversion were found to be the main predictors of WTC in L2 acquisition, while were not significant when analyzing unwillingness to communicate (UWTC) in the context of English as a foreign language (ESL) [26]. According to some authors who analyzed the role of personality traits and integration process of migrants, an increase in L2 proficiency appears to be related to a positive change in terms of identification, regardless of sojourners' personality traits [27]. Some studies were made about openness and L2 willingness to communicate, where this variable was proven to explain up to $21 \%$ of L2 WTC in a multiple regression model [28]. Application of the Enneagramm was made to fill the gap between personality traits and the acquisition process of another language, in this case English [29]. Previous studies were made on extraversion versus introversion about focus on form episodes. A FFE was defined as a series of utterances between the teacher and a student where students' attention was drawn to linguistic form either reactively or preemptively [30]. After a general review of the attempts made to make correlation between personality traits and L2 acquisition process, which is one of the variables relevant to our research.

\section{Materials and methods}

On the basis of the theoretical knowledge, corroborated by the everyday experience provided by our students we wanted to measure a correlation between extraversion, motivation and approach to Russian Language.

Table 1. Time of completion

\begin{tabular}{|l|l|}
\hline Time & Percentage of the sample \\
\hline $2-5$ min & $2 \%$ \\
\hline $5-10$ min & $67 \%$ \\
\hline $10-30$ min & $31 \%$ \\
\hline
\end{tabular}

We did not want to analyze the phenomenon within our classes, because learning L2 in a foreign speaking environment would not have provided the data we wanted to get from students. Therefore we wanted to test some foreign audience who is in the process of studying the language we teach. The potential respondents had to be found by abroad. The contact method used substantially two.

a) Asking for mailing list from our colleagues from Italian universities.

b) Using social media (WhatsApp and Facebook) to get direct contact with the population of our research.

Only a part of the contacts was willing to respond to our questionnaire(s). The overall sample actually responding to our request $(n=48)$ comes from the Russian language courses of three Italian high-rated universities, University of Bari. Ca' Foscari of Venice and University of Parma. This choice was dictated not merely by change but by the support found from our colleagues and from the responsiveness of the students. To overcome the problem of distance and to avoid students to deal with printed research, both to easy the compilation and not to waste paper we chose to make an online survey to which a link was associated and sent to the potential repliers. The survey was made in Italian, the native language of the student we were interested to test, and composed of three different sub-surveys.

The whole questionnaire was divided into 3 parts, the first part was aimed to evaluate the personality of the student (introverted/extraverted), the second was expected to score the motivation, while the third analyzed the personal approach to L2 learning, with particular reference to the Russian language. All the three parts, analyzed in details further, are composed by a Likert scale type of 4 answers. To get the final score for each test, to each answer was given a value from 1 to 4 in accordance with the item subject to the investigation. In the table below we report the average time of completion, which for the majority was between 5 and 10 minutes. 
After an evaluation of the single scores for each survey questionnaire reconciliation of all the variable was made using multiple regression analysis.

\section{Results}

The first questionnaire determined the overall tendency of the student to be introvert or extrovert. It is formed by 28 questions, each related to four answers made on a Likert scale base (strongly disagree, disagree, agree, strongly agree). For simplification in the determination of the final score, to each answer was attributed a score from 1 to 4 , where $1=$ introvert and $4=$ extrovert. To those questions stated negatively the score was reversed in order not to make a senseless final score. The least possible score (28) was attributable to a strongly introverted personality, while the highest possible score (112) was associated with a strongly introverted one. The number of bins for the qualitative analysis was calculated using the Sturges' rule:

$$
\left(k=1+3.3 \log _{10}(n)\right) \text {. }
$$

The histogram below shows the result in qualitative terms.

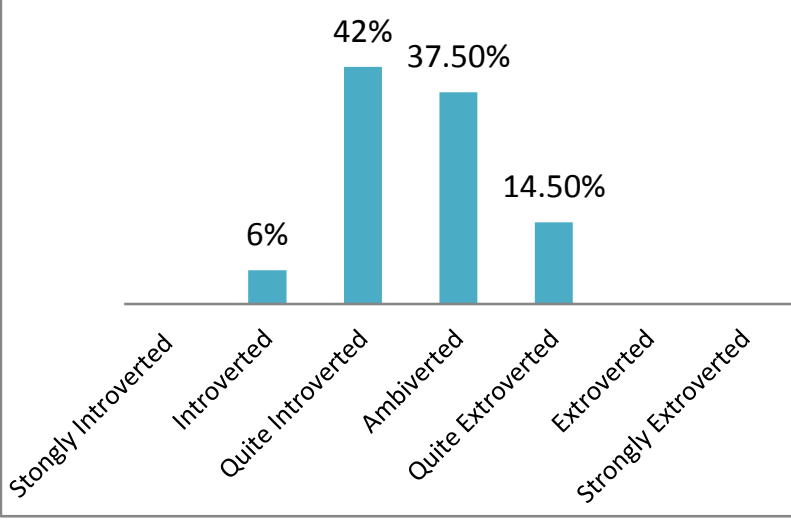

Graph 1. Introversion-Extroversion in percentage

The overwhelming majority of the sample is included within the third and the fourth bin, from a qualitative point of view, according to the data gathered in this research, we may say that the majority of Italian students who decide to study Russian are not extroverts. There can be an explanation for this, coming from the practical everyday approach with students. Generally, those who chose Russian are attracted by the cold weather and literature works with a particular introspective approach of Dostoevsky and Tolstoy, which per se are signals of introversion.

Let us now make some inference on the results from a quantitative point of view.

Table 2. Descriptive statics for questionnaire 1

\begin{tabular}{|l|l|}
\hline Mean & 64.93 \\
\hline SD & 1.32 \\
\hline Skewness & 0.13 \\
\hline
\end{tabular}

\begin{tabular}{|l|l|}
\hline Confidence level for $95 \%$ & 2.66 \\
\hline Cronbach's $\alpha$ & 0.81 \\
\hline
\end{tabular}

From these data we can make some inference on the questionnaire itself. The mean and the confidence interval tell us that the results are strongly concentrated between the quite introverted and the ambiverted psychotype, since a score of 64 is the bench mark between the two bins spotted in the graph above. The Cronbach's alpha is high, giving to our research a highly reliable level of internal consistency from a statistical point of view.

The second questionnaire was made to find out the level of motivation of each student. It comprises 13 questions, each followed by a Likert scale score system; the possible answers were: strongly disagree, disagree, agree, strongly agree. For simplification in the determination of the final score, each answer was attributed a score from 1 to 4 , where $1=$ demotivated and $4=$ motivated. To those questions stated negatively the score was reversed to avoid errors in the final score. Straightforwardly, the least possible final score was 13 while the highest possible was 52. Also for this questionnaire we use 7 bins, because the Sturges' rule depends on the number of the respondents and not on the number of questions. The results for qualitative analysis are easily readable in the graph below.

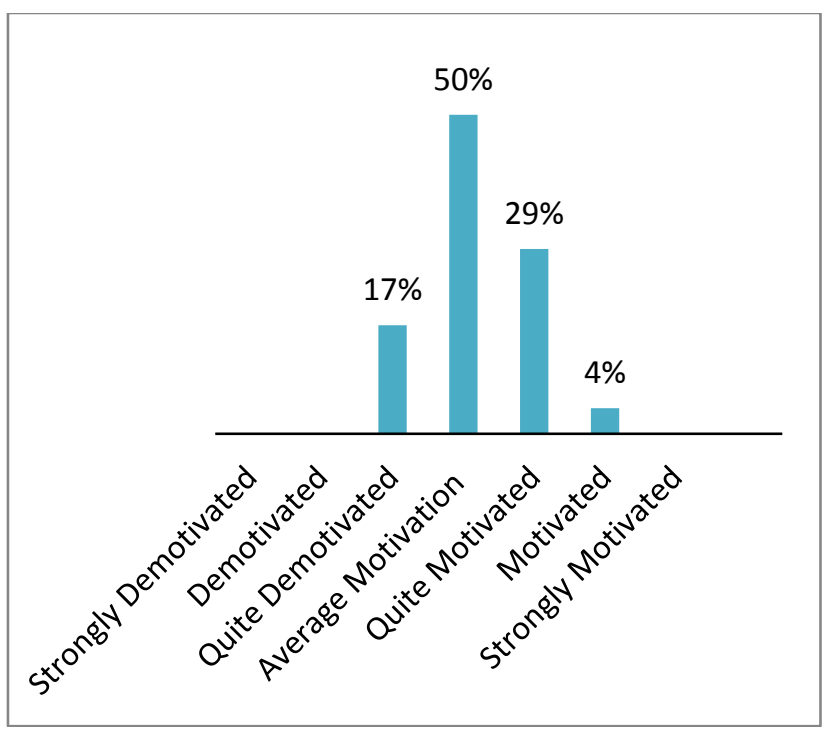

Graph 2. Motivation level in percentage

Precisely half of the sample is included in the middle between demotivated and motivated. If we look at the previous graph, we will notice that the concentration in this distribution is also centered around the three bins in the center. According to data, we should say that the Italian students who are involved in the learning process of Russian language are more motivated than demotivated (32\% against $17 \%$ ), if we exclude half of the sample for which we do not have a particular inclination when analyzing this variable. Actually motivation is a key factor when studying a language so different (according to the Italian students) from the mother tongue. Likely, an Italian student choosing French or Spanish is less motivated than another one who wants to study Chinese, the Russian choice should be somewhere in the middle. 
However, at the moment we lack in evidence to state that motivation is a positive function of L2 distance from L1. Let us make some descriptive statistical analysis on what we have found.

Table 3. Descriptive statistics for questionnaire 2

\begin{tabular}{|l|l|}
\hline Mean & 34.4 \\
\hline SD & 4.6 \\
\hline Skewness & 0.19 \\
\hline Confidence level for 95\% & 1.34 \\
\hline Cronbach's $\alpha$ & 0.64 \\
\hline $\begin{array}{l}\text { Correlation coefficient with } \\
\text { extroversion }\end{array}$ & 0.19 \\
\hline
\end{tabular}

The mean is concentrated within the central bin, the standard deviation is higher here than that in the previous questionnaire. However, as the confidence level low, we can still consider the distribution highly concentrated around the central bin. The skewness of this distribution is negative, as we can observe by the graphical representation. Alpha for this questionnaire is less consistent than that for the first one, but still enough high to make this questionnaire reliable from a point of view of internal variance among the single items and the total score. A correlation coefficient was found with the previous distribution function, denoting a positive correlation between the two variables.

The third questionnaire was not a test of the Russian language, our aim was to test not the knowledge, but the approach to the Russian L2 acquisition. We made 13 questions based on the practical experience of the learning process to see how the student learn a language and how difficult they find some of the general rules of Russian grammar. It consisted of 13 questions which included a Likert scale score system form "strongly disagree" to "strongly agree", to each of those questions a score from 1 to 4 was assigned, where $1=$ very poor approach to Russian L2 and 4= very good approach to Russian L2. The distribution of qualitative scores is depicted in the graph below.

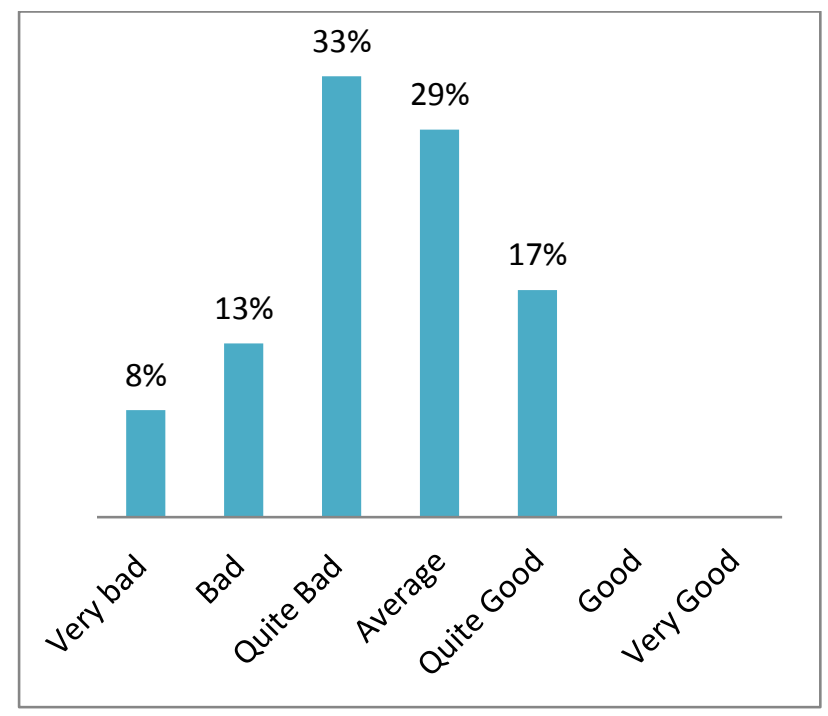

Graph 3. Approach to Russian L2 in percentage
From the graph above we can observe that there is much more variability among the bins with respect to the graphs about psychotypes and motivation. Data depict a quite pessimistic scenario about the matter, with the majority of the sample concentrated on the third and the fourth bin. If we exclude the central bin, we can see that more than half of the sample (54\%) is distributed in the left part of the graph, to which an overall bad approach is attributed. Data from practical experience, gathered at every lesson, may confirm this scenario.

\section{Discussion}

The approach to Russian language L2 from the Italian student is not so good for a series of reasons. The most valuable ones are the overall problems with:

a) The use of cases (nominative, genitive, prepositional, accusative, dative and instrumental).

b) The system of verbs and tenses (perfective and imperfective).

Both variables influence negatively the approach to learning Russian because they are perceived as difficult and far from the Italian grammatical system.

The very majority dedicate not enough time to study, less than an hour a day, which is partially the cause and the result of difficulties to improvement. Even if the majority stated that they liked more the speaking than the mere study of grammar, just a small part of the sample made efforts to improve speaking because:

a) They wait to know all the rules before trying to make some oral sentences in public.

b) They do not search for a mother tongue "pen pal" to practice language, even if they are active on social media.

Let us now make some inference on data about the third and last questionnaire, the data are arranged in the table below.

Table 4. Descriptive statistics for questionnaire 3

\begin{tabular}{|l|l|}
\hline Mean & 29.7 \\
\hline SD & 6.4 \\
\hline Skewness for & -0.32 \\
\hline $\begin{array}{l}\text { Confidence level } \\
\text { 95\% }\end{array}$ & 1.85 \\
\hline Cronbach's $\boldsymbol{\alpha}$ & 0.8 \\
\hline $\begin{array}{l}\text { Correlation coefficient } \\
\text { with extroversion }\end{array}$ & -0.12 \\
\hline $\begin{array}{l}\text { Correlation coefficient } \\
\text { with motivation }\end{array}$ & 0.13 \\
\hline
\end{tabular}

From statistical inference we may depict a mean around 30, which is the benchmark between quite bad and average, confirming a tendency to the bad approach from the students, but the standard deviation is quite high, as seen in the graph the internal variability is higher with respect to the previous distributions. Small confidence intervals says that the overwhelming majority of the population is between the third and the fourth bin. The high level of alpha gives a high reliability of the questionnaire in terms of internal consistency. The coefficients were calculated separately with the simple linear regression approach, it seems that the approach to 
Russian is positively correlated with motivation but negatively with extroversion, but what happens if we put the three variables in the same model?

A final multiple regression analysis was made for the three variables: extroversion, motivation and approach to Russian L2. Data founded are as reported in the table below.

Table 5. Multiple regression analysis for the three variables

\begin{tabular}{|l|l|l|l|}
\hline & Coefficients & t Stat & P-value \\
\hline Intercept & 29 & 3.27 & 0.002 \\
\hline Extrovertion & -0.11 & -1.03 & 0.304 \\
\hline Motivation & 0.22 & 1.08 & 0.283 \\
\hline Multiple R & 0.20 & & \\
\hline
\end{tabular}

Above you can observe the coefficient for the dependent variable extroversion and motivation for the independent variable approach to Russian L2. The sign of the coefficients is the same as it was for the correlation saw in table 4, confirming approach to Russian L2 as a positive function of motivation but a negative for extroversion. The overall reliability of the model is expressed by the multiple $\mathrm{R}$ in the table.

\section{Conclusions}

To sum up, we started from the review of the literature about the correlation between personality traits and L2 learning, then we described the bonds between the personality and the teaching method, which come from the everyday experience, however it was not enough. With the resources available, in terms of time, knowledge of the population analyzed and research instruments we attempted to find a correlation with the use of the multiple regression model approach to three qualitative variables, whose results were reported above. This work, based on our research on the main scholar research databases (Scopus and Wos), is the first attempt to make such analysis for Russian language as L2 in a context outside the language environment. The limitations are set by the time required to make the research and by the actual response of students. Despite the relatively high population, few students were actually eager to spend their free time answering our questionnaire. We hope this research would be a hint for our colleagues to study the matter and find more suitable models to explain the phenomenon. A good idea would be to work with the colleagues of the main universities where Russian is taught and make some high-scale statistic research, even if it is really difficult to reach cooperation agreement with fellow scholars of other countries, as well as to find students who approach seriously the questionnaires and research.

This publication has been prepared with the support of the "RUDN University Program 5-100"

\section{References}

1. Z. Boo, Z. Dornyei, S. Ryan, Sy., L2 motivation research 2005-2014: Understanding a publication surge and a changing landscape, 55, 145-157(2015).

2. T. Scovel, Lang. Lear., The effect of affect on foreign language learning: A review of the anxiety research, 28, 129-142 (1978).

3. R.C. Gardner, Social psychology and second language learning: The role of attitudes and motivation (Edward Arnold, London, 1985).

4. E.K. Horwitz, M.B. Horwitz, J. Cope, T. Mod. Lang. J., Foreign language classroom anxiety, 70, 125-132 (1986).

5. B. Carroll, S.M. Sapon, Modern Language Aptitude Test: MLAT (Psychological Corporation, New York, 1959).

6. B. Carroll, S.M. Sapon, Modern Language Aptitude Test, Elementary Form (Psychological Corporation, New York, 1967).

7. P. Pimsleur, Pimsleur Language Aptitude Battery (Harcourt Brace Jovanovitch, New York:, 1966).

8. R.L. Sparks, L. Ganschow, The Mod. Lang. J., Foreign Language Learning Differences: Affective or Native Language Aptitude Differences?, 75, 3-16 (1991).

9. R.C. Gardner, W. E. Lambert, Can. J. of Psy., Motivational variables in second language acquisition, 13, 266-272 (1959).

10. R.C. Gardner, Language learning motivation: The student, the teacher, and the researcher. Proceedings of the Texas Foreign Language Education Conference. University of Texas, Austin, 2001).

11. E. K. Horwitz, M.B. Horwitz, J. Cope, T. Mod. Lang. J., Foreign language classroom anxiety, 70, 125-132 (1986).

12. R. Clement, R. C. Gardner, P. C. Smythe, Can. J. of Be. Sc., Social and individual factors in second language acquisition, 12, 293-302 (1980).

13. R. Clement, Ethnicity, contact and communicative competence in a second language. In H. Giles, W.P. Robinson, P.M. Smith (Eds.), Language: Social psychological perspectives,147-154 (Pergamon, Oxford, England,1980).

14. R. Clement, J. of Lang. and Soc. Psy., Second language proficiency and acculturation: An investigation of the effects of language status and individual characteristics, 5, 271-290 (1986).

15. R. Clement, Z. Dornyei, K.A. Noels, Lang. Lear., Motivation, self-confidence, and group cohesion in the foreign language classroom, 44,417-448(1994).

16. R. Clement, R.C. Gardner, P.C. Smythe, Can. J. of Be. Sc., Motivational variables in second language acquisition: A study of Francophones learning English, 9, 123-133 (1977).

17. R. Clement, B.G. Kruidenier, J. of Lang. and Soc. Psy., Aptitude, attitude and motivation in second 
language proficiency: A test of Clement's model, $\mathbf{4}$, 21-37(1985).

18. P. D. MacIntyre, C. Charos, J. of Lang. and Soc. Psych, Personality, Attitudes, and Affect as Predictors of Second Language Communication, 15, 3-26 (1996).

19. K. Ożańska-Ponikwia,Sec. Lang. Lear. and Te., Extraverts and introverts in the FL classroom setting, 93-105(2017).

20. G. Ockey, Lang. Lear., Self-consciousness and assertiveness as explanatory variables of L2 oral ability: A latent variable approach, 61, 968989(2011)

21. Z. Kralova, Kom., A probe into extraversion and L2 pronunciation relationship, 14, 29-36 (2012).

22. J.M. Deawele, Mod. Lang. J., The link between foreign language classroom anxiety and psychoticism, extraversion, and neuroticism among adult Bi- and multilinguals, 97,3, 670-684(2013).

23. N. Taguchi, As. EFL J., Personality and development of second language pragmatic competence, 16, 203221 (2014).

24. M. Souzandehfar, S.M.A. Soozandehfar, M. Farsi, M. Sharif, Adv. in Env. Bio., Which personality trait performs better on IELTS speaking test? Extroverted or introverted?, 8, 2159-2168 (2014).

25. H. Oz, Soc. Beh. and Pers., Big Five Personality Traits And Willingness To Communicate Among Foreign Language Learners In Turkey, 42, 1473-1482 (2014).

26. R. Khany, A.M. Nejad,T. Iran. EFL Context. RELC J., L2 Willingness to Communicate, Openness to Experience, Extraversion, and L2 Unwillingness to Communicate, 48, 241-255 (2017).

27. C.van Niejenhuis, S.Otten A. Flache, Int. J. of Inter. Rel., Sojourners' second language learning and integration. The moderating effect of multicultural personality traits. 63, 68-79 (2018).

28. E. Piechurska-Kuciel, Sys., Openness to experience as a predictor of L2 WTC., 72, 190-200 (2018).

29. C. Coker, F. Mihai, TESOL J., Personality Traits and Second Language Acquisition: The Influence of the Enneagram on Adult ESOL Students, 8, 432449(2017).

30. J. Kim, H. Nassaji, Lang. Teach. Res., Incidental focus on form and the role of learner extraversion, 22 , 6, 698-718(2018). 